\title{
A SUBSTITUIÇÃO TRIBUTÁRIA NA JURISPRUDÊNCIA BRASILEIRA / THE TAX SUBSTITUTION IN BRAZILIAN CASE LAW
}

Fabiano Soares Gomes ${ }^{1}$

\begin{abstract}
Resumo
O presente artigo busca discutir o fenômeno da substituição tributária no direito brasileiro. Discute-se aqui a razão de ser desse instituto jurídico, a chamada sujeição passiva tributária passiva tributária antecipada, ou substituição tributária "para frente", e, particularmente quanto à essa substituição tributária "para frente", o entendimento dos Tribunais Superiores quanto a esta matéria.

O artigo conclui pela veemente repulsa à utilização do mecanismo da substituição tributária "para frente". Malgrado ser um excelente instrumento para a administração tributária e para a sanha arrecadadora do Estado, o instituto parece chocar-se frontalmente com a sistemática constitucional.
\end{abstract}

Palavras-chave: Substituição tributária. Sujeição passiva tributária antecipada. Constitucionalização dos direitos.

\begin{abstract}
This paper discusses the phenomenon of tax substitution in Brazilian law. Here we discuss the legal nature of this legal institution, discusses the so called tributary passive advance subjection or tax substitution "forward", and particularly as to this tax substitution "forward", the understanding of the Superior Courts about this matter.

The article concludes by vehement revulsion to the use of the mechanism of tax substitution "forward". Despite being an excellent tool for tax administration and tax collecting of the state, the institute seems to clash head-on with constitutional systematic.
\end{abstract}

Keywords: tax replacement. Tax substitution. Tributary passive advance subjection. Constitutionalization of rights.

1. Introdução

Ricardo Lobo Torres, no início de seu Curso de Direito Financeiro e Tributário, tece interessantes e precisas considerações sobre a evolução histórica da concepção de Estado, e, conseqüentemente, dos mecanismos de que se valeu para seu sustento. Nesse sentido, desenvolve e defende a idéia de que com o fim da ordem bipolar no início dos anos 90 fortalece-se o Estado Democrático e Social Fiscal, que mantém "características do Estado Social, mas passa por

\footnotetext{
${ }^{1}$ Mestre em Direito Público pela UERJ. Advogado no Rio de Janeiro.
} 
modificações importantes, como a diminuição do seu tamanho e a restrição ao seu intervencionismo no domínio social e econômico ${ }^{2}$, vivendo primordialmente, destarte, dos ingressos tributários.

Como consequiência desta nova mentalidade acerca do papel do Estado e dos mecanismos que este se utiliza para arrecadar receita - sobretudo através da figura dos tributos - a fim de atender as necessidades públicas, sobreleva o interesse da comunidade acadêmica e da sociedade civil, especialmente nos fóruns de debate político e jurídico, assuntos como, entre outros, orçamento, política fiscal e tributação. Com efeito, é flagrante a evolução da doutrina brasileira, nestes últimos 15 anos, em matéria de Direito Financeiro - e do qual o Direito Tributário é espécie -, que cada vez mais busca inspiração em fontes de direito comparado, cometendo com isso vez por outra algumas atrocidades jurídicas, mas especialmente observando a própria história e técnica tributária, aperfeiçoando-as.

Nesse contexto, evidencia-se a relação dialética entre Estado e particular, respectivamente o credor e o devedor da obrigação tributária, esta definida por PAULO DE BARROS CARVALHO como o vínculo surgido com a concretização de um fato jurídico que, por estar descrito no antecedente de uma norma individual e concreta de imposição de um tributo, denomina-se fato jurídico tributário ${ }^{3}$. Assim, mister se faz, para melhor compreender um fenômeno de importância cada vez mais topográfica no direito brasileiro, realizar aquilo que LUís QUEIROZ objetivou como “(...) surpreender a sucessão de acontecimentos cuja ocorrência é necessária para o nascimento da 'obrigação tributária', determinada e individualizada $(\ldots)^{3}$ ', nos seus três planos: normativo, fático e relacional.

O plano normativo é aquele que se debruça sobre a norma jurídica impositiva tributária, com o seu desdobramento didático em antecedente - afigurando-se a previsão geral e abstrata de determinada conduta, de natureza condicionante -, e conseqüente - parte condicionada da norma jurídica tributária que impõe determinado resultado jurídico àquele que realizou a conduta descrita no antecedente da norma -, com seus respectivos critérios pessoal, material, temporal e espacial. Por sua vez, o plano fático, ou do fato jurídico tributário, é aquele que se volta à realização concreta daquela conduta prevista na norma jurídica tributária, e que implicará na formação do terceiro plano de acontecimentos capazes de formar a obrigação tributária, qual seja o plano relacional. Por

\footnotetext{
${ }^{2}$ TORRES, Ricardo Lobo. Curso de Direito Financeiro e Tributário, 12. ${ }^{\text {a }}$ ed. Rio de Janeiro: Ed. Renovar, 2005 , p. $9 .{ }^{3}$ CARVALHO, Paulo de Barros. Curso de Direito Tributário, 17ª ed. São Paulo: Ed. Saraiva, 2005, p. 295.

${ }^{3}$ QUEIROZ, Luís Cesar Souza de. Sujeição Passiva Tributária. Rio de Janeiro: Ed. Forense, 2002, p. 163. ${ }^{5}$ Op. cit., p. 232.
} 
fim, como bem sintetiza Luís QUEIROZ, “A relação jurídica é projeção, enriquecida de determinação e de individualização, do conseqüente da norma jurídica abstrata e geral, assim como o fato jurídico é projeção, enriquecida de concretude, do antecedente da norma abstrata e geral ${ }^{5}$ ".

De toda forma, é premissa de existência da obrigação tributária - e, portanto, também dos planos normativo, fático e relacional que a compõe - a existência de dois sujeitos dessa obrigação: um ativo, representando o credor da referida obrigação - o Estado -, e um passivo, representando o respectivo devedor da mesma - o contribuinte sujeito de direito que se submete à determinação de entregar parcela de riqueza que aufere para a manutenção do Estado, que a utilizará na consecução de sua atividade financeira. Daí falar-se em sujeição passiva tributária, que nada mais é do que aquele sujeito de direito que, identificado pelo critério pessoal passivo do conseqüente da norma tributária - esta, por seu turno, necessariamente informada e condicionada pelo Princípio Constitucional da Capacidade Contributiva, corolário do Princípio da Igualdade - tem o dever jurídico de entregar ao Estado parcela de riqueza pessoal de que é titular, segundo a descrição contida no aspecto material do antecedente da norma ${ }^{4}$.

Contudo, nem sempre ocorre de o valor a ser recolhido por determinado sujeito passivo a título de tributo ser entregue ao Estado de forma direta - como é o caso, por exemplo, do Imposto Predial e Territorial Urbano (IPTU), em que o devedor do imposto deve ativamente retirar de seu patrimônio aquele montante suficiente para entregá-lo à Municipalidade, conforme preceito do art. 156 da Constituição Federal e arts. 32 a 34 do Código Tributário Nacional. Por permissivo constitucional e respectivo tratamento no CTN, pode a lei, respeitados os limites da permissão constitucional, atribuir o dever de entregar a parcela de riqueza devida pelo contribuinte a um terceiro, por razões alheias à relação jurídica tributária constituída entre o sujeito passivo “direto" e o Fisco. Essa é a hipótese daquilo que se convencionou denominar substituição tributária, que se passa a tratar mais detidamente a seguir.

\section{A Substituição Tributária}

Nas palavras de RICARDO LOBO TORRES, "Substituto é aquele que, em virtude de determinação legal, fica em lugar do contribuinte, assumindo a responsabilidade pela obrigação tributária. O conceito de substituição se subsume na definição do art. 128 do CTN: a lei pode atribuir de modo expresso a responsabilidade pelo crédito tributário a terceira pessoa, vinculada ao

\footnotetext{
${ }^{4}$ Luís Cesar Souza de QUEIROZ, Sujeição,p. 230.
} 
fato gerador da respectiva obrigação, excluindo a responsabilidade do contribuinte ${ }^{5 \%}$. Um exemplo clássico e particularmente doutrinariamente incontroverso de substituição tributária - apesar de nem por isso ser placidamente aceita enquanto legítimo mecanismo de política tributária de arrecadação - é o da retenção na fonte do imposto sobre a renda ou do ISS.

No entanto, apesar de ser um terceiro o responsável pela arrecadação do tributo, em substituição ao contribuinte, é de boa doutrina compreender que não se trata de qualquer terceiro que pode figurar enquanto substituto da obrigação tributária principal. Ao revés, necessariamente contribuinte e substituto devem estar participando de um mesmo processo econômico que enseje relação de causalidade suficiente a justificar a relação de substituição. Contudo, de se asseverar, conforme bem observado por RICARDO LOBO TORRES, “entre o substituído e o substituto não existe nenhum vínculo de natureza tributária ${ }^{6}$, , e isso se deve exatamente pelo fato pela natureza jurídica do regime da substituição não ser intrínseca e ontologicamente tributária, mas mais de administração e política de arrecadação tributárias. No mesmo sentido insiste Luís Queiroz afirmando que “(...) contribuinte é o único sujeito de direito que figura no pólo passivo da relação jurídica tributária"\%.

O que justifica a criação e a existência da substituição tributária é uma razão de cunho pragmático, de natureza meramente administrativa, motivada pela grande dificuldade do Fisco em arrecadar, recolher e fiscalizar o pagamento dos tributos devidos pelo contribuinte, seja pela informalidade, pela ilicitude ou mesmo pela enorme pluralidade destes. Como bem aponta Luís QUEIROZ,

"O instituto da substituição tributária tem por fundamento o atendimento do interesse da chamada 'Administração Tributária'. (...) Daí surgir o regime jurídico da substituição tributária que se justifica, basicamente, por três importantes motivos:

a) pela dificuldade em fiscalizar contribuintes extremamente pulverizados;

b) pela necessidade de evitar, mediante a concentração da fiscalização, a evasão fiscal ilícita; e

c) como medida indicada para agilizar a arrecadação e, conseqüentemente, acelerar a disponibilidade de recursos 8 ,

Já PAUlo De BARRos CARVALHO advertia que "a modificação se produz antes que o texto seja editado, em tempo que antecede o aparecimento da disciplina jurídica sobre a matéria. Estamos diante de algo que se opera em intervalo meramente político, quando o legislador prepara sua

\footnotetext{
${ }^{5}$ Op. cit., p. 262.

${ }^{6}$ Op. cit., p. 262.

${ }^{7}$ Op. cit., p. 199.

${ }^{8}$ Op. cit., p. 199.
} 
decisão e a norma ainda não logrou entrar no sistema"'. Tal noção é corroborada com o exemplo proposto por LOBO TORRES, ao tratar da questão da substituição tributária no ICMS, da indústria de laticínio em relação à aquisição de leite in natura dos produtores rurais, "em que o industrial, melhor organizado empresarialmente, se torna substituto do produtor rural, que não tem possibilidade de emitir notas fiscais e manter escrituração contábil ${ }^{10 "}$.

Entretanto, assim como é necessário algum nexo relacional entre substituto e substituído, o legislador está vinculado a algumas premissas constitucionais para prever a substituição tributária, bem lembradas por Luís QueIroz ${ }^{11}$ das lições de GERALdo AtALIBA, Aires F. BARRETO, AlFrEdO Becker, Paulo de Barros Carvalho e Ricardo lobo Torres quais sejam as de que i) o regime jurídico aplicável é o do substituído, e não o do substituto; ii) a lei tributária aplicável à obrigação tributária é o das operações substituídas, e não as da operação do substituto; e iii) que sejam previstos mecanismos eficazes ao pleno e rápido ressarcimento do substituto, em respeito aos princípios constitucionais da igualdade, da capacidade econômica, da vedação ao confisco e da específica individualização constitucional do sujeito passivo do tributo.

Destarte, é de se admitir duas hipóteses em que o regime da substituição tributária harmoniza-se com o ordenamento constitucional-tributário: 1) a de que o contribuinte entregue ao substituto o valor a ser recolhido por este, enquanto agente arrecadador do Estado, a título de tributo; ou 2) que o substituto, de posse de riqueza do contribuinte (hipóteses de retenção na fonte de Imposto sobre a Renda), retire a quantia que cabe ser repassada ao Fisco. De outra forma, configurar-se-ia a situação em que o substituto teria que retirar do próprio patrimônio o montante devido pelo substituído ao Estado, o que seria flagrantemente inconstitucional por ferir sobretudo os princípios mencionados supra.

Malgrado todas as facilidades que esse instrumento traz ao Fisco, vem despertando grande interesse doutrinário e uma verdadeira cruzada judicial a figura quase mitológica da sujeição passiva tributária antecipada, ou "substituição tributária 'para frente", bastante própria da substituição na arrecadação do ICMS, que ocorre quando o tributo é recolhido antes da ocorrência do fato jurídico tributário propriamente dito. Apesar de, em relação ao ICMS, admitir-se também a substituição tributária "para trás" - quando o substituto adquire mercadoria do efetivo contribuinte, mas em virtude de razões econômicas particulares assume a responsabilidade do pagamento do

\footnotetext{
${ }^{9}$ Citado por Luís Cesar Souza de QUEIROZ, Sujeição, p. 196.

${ }^{10}$ Op. cit., p.

264.

${ }^{11}$ Op. cit., p. 199-

200 .
} 
tributo devido -, como bem ressalta LOBO TORRES ${ }^{12}$, esta modalidade substitutiva não provoca grande atenção da doutrina desde que exista vinculação entre substituto e substituído, através da situação que constitua a obrigação principal. Porém, como se observou, o mesmo não ocorre na substituição tributária "para frente", e exatamente por essa seu caráter controverso e por sua complexidade teórica é que o instituto merece que para ele se atente mais detidamente.

\section{A Sujeição Passiva Tributária Antecipada}

Mais uma vez se faz precisa a lição de RICARDO LOBO TORRES, que define a sujeição passiva tributária antecipada, ou substituição tributária "para frente", como a hipótese de "quando uma terceira pessoa, geralmente o industrial, se responsabiliza pelo pagamento do tributo devido pelo comerciante atacadista ou varejista, que revende a mercadoria por ele produzida. É o caso, por exemplo, da indústria do cigarro, que substitui o comerciante varejista na obrigação principal, recolhendo desde a saída da mercadoria do estabelecimento industrial o imposto incidente na ulterior operação com o consumidor final ${ }^{15}$ ",

Historicamente, o instituto surgiu previsto no corpo do Código Tributário Nacional (Lei n. ${ }^{\circ}$ 5.172, de 25 de outubro de 1966) - em seu art. 58, § 2. ${ }^{\circ}$, II - que dispunha, literalmente, que a lei poderia atribuir a condição de responsável "ao industrial ou comerciante atacadista, quanto ao imposto devido pelo comerciante varejista, mediante acréscimo, ao preço da mercadoria a ele remetida, de percentagem não excedente de $30 \%$ (trinta por cento) que a lei estadual fixar". A redação desta disposição do CTN foi posteriormente alterada pelo Ato Complementar n. ${ }^{\circ}$ 34, de 30 de janeiro de 1967, e finalmente revogada pelo art. 13 do Decreto-Lei n. ${ }^{\circ}$ 406, de 31 de dezembro de 1968. Contudo, em dezembro de 1983 foi editada a Lei Complementar n. ${ }^{\circ}$ 44, que, acrescentando parágrafos aos arts. $2^{\circ}, 3^{\circ}$ e $6^{\circ}$, reincorporou o instituto da substituição tributária "para frente" ao ordenamento brasileiro. Dessa forma, é de se reconhecer que não se trata de um instituto estranho à tradição tributarista brasileira.

Contudo, a promulgação da Constituição de 1988, que bem ao gosto daquele ímpeto justo, mas em alguns casos exagerado - que DANIEL $\mathrm{S}_{\text {ARMENTO }}{ }^{13}$ denominou de ubiqüidade

\footnotetext{
${ }^{12}$ Op. cit., p. 264.

15 Idem.

${ }^{13}$ SARMENTO, Daniel. Ubiqüidade Constitucional: os dois lados da moeda. Rio de Janeiro: Revista de Direito do Estado, n. 2, abril/junho de 2006, pp. 83-118. 17 Em que se poderia citar a título de exemplificação, entre outros, Geraldo Ataliba, Aires F. Barreto, Hamilton Dias de Souza, Ives Gandra Martins, Paulo Barros Carvalho e Luís Queiroz.
} 
constitucional, deu grande relevo à exaustiva regulação da ordem financeira e tributária, sobretudo aos seus princípios norteadores, de elevada carga axiológica, mas, conforme os bons ventos das doutrinas de Konrad Hesse, Robert Alexy e outros, de natureza condicionante e vinculante da legislação infra-constitucional e, até, dos eventuais processos de reforma constitucional. Dessa forma, erigiram-se como capitaneadoras do sistema tributário, entre outras, as premissas da igualdade, da capacidade contributiva, da individualização do sujeito passivo tributário, da objetividade do fato gerador e da vedação ao confisco. Com isso, apesar de a sistemática da sujeição passiva antecipada já estar profundamente arraigada na comunidade jurídica brasileira, primeiros indícios começaram a surgir de que este instrumento arrecadador não mais se conformava à nova ordem constitucional. Desta forma, constitucionalistas e tributaristas impelidos pelos novos ventos trazidos com a Constituição Federal de $1988^{17}$, ao depararem-se com a "inovação" trazida pela Emenda Constitucional n. ${ }^{\circ} 3 / 93$, que acrescentou o $\S 7 .^{\circ}$ ao art. 150 da Carta - que veio tardiamente na tentativa exatamente de conferir legitimidade constitucional à malfadada prática da substituição tributária "para frente" -, insurgiram-se em defesa da coerência da ordem jurídicoconstitucional e das garantias fundamentais previstas no texto constitucional.

Assim, é de certa forma descabida a perplexidade do Ministro ANTÔNIO DE PÁDUA RIBEIRO, que em palestra proferida em 21 de junho de $1996{ }^{14}$ confidenciava não compreender a revolta de sólidos doutrinadores com a substituição tributária "para frente". Pelo contrário, e sem aqui emitir qualquer juízo de valor, a defesa apaixonada por um instituto de administração tributária está mais para uma lógica estatista de tempos passados e, assim se espera, findos, do que para a defesa das liberdades individuais e dos direitos fundamentais que foi proposta pela Constituinte de 1987-88 e abraçada pela sociedade e pela comunidade jurídica por todo o Brasil. Data venia, de forma análoga não se sustenta o argumento de ÂNGELO DE MELO, de que "o dogma da verdade absoluta, da certeza absoluta, da realidade fática simples e crua, tem de sofrer certa relativização num mundo hodierno que passa pela era da globalização ${ }^{15}$ ". Desejasse o Constituinte originário e a sociedade que o direito fosse extraído pragmática e instrumentalmente de circunstância contingentes, subjetivas e fugazes, não tivesse promulgado uma Constituição tão rígida e tão

\footnotetext{
${ }^{14}$ RIBEIRO, Antônio de Pádua. Substituição Tributária para Frente. Brasília: Revista CEJ, vol. 1, n. ${ }^{\circ}$ 3, set./dez. de 1997, p. 105-110. Neste mesmo evento, o Ministro Antônio de Pádua Ribeiro sustentou ainda que a sujeição passiva tributária teria sido acolhido pela Constituição Federal de 1988, interpretando que o art. 155, § 2. ${ }^{\circ}$, XII, b, da Carta acolheu o Convênio 66/88 (sendo que este teria incluído em seu texto as normas da Lei Complementar n. ${ }^{\circ} 44$, de 1983 ), que, para o palestrante, teria força de lei complementar por imperativo do art. $34, \S 8 .^{\circ}$ do ADCT. Tal argumento seria perfeitamente correto não fossem as próprias limitações constitucionais ao sistema tributário, que rechaçam o núcleo material da sujeição passiva antecipada.

${ }^{15}$ DE MELO, Ângelo Braga Netto Rodrigues. ICMS: Substituição Tributária Progressiva após a ADIn 1.851-4/AL - a Questão da Legitimidade dos Subsídios para Questionar a Base de Cálculo Presumida. São Paulo: Revista Dialética de Direito Tributário, n. ${ }^{\circ}$ 102, março de 2004, pp. 20.
} 
democrática: melhor seria ter consagrado somente o "führerprinzip" e muito dos problemas que hoje atormentam a comunidade jurídica sequer existiriam.

Em todo caso, não obstante respeitável entendimento em sentido diverso, e aí se inclui o da maioria dos ministros do Supremo Tribunal Federal, não só por uma maior afeição ao rigor e à higidez da dogmática tributária, mas especialmente em deferência aos princípios constitucionais que informam e vinculam o ordenamento jurídico pátrio é que se faz oportuno desposar dos argumentos que concluem pela "inconstitucionalidade" da admissibilidade da sujeição passiva antecipada e, conseqüentemente, da Emenda Constitucional n. ${ }^{\circ} 3 / 93$, que introduziu o $\S 7 .^{\circ}$ ao art. 150 da Carta Magna.

LOBO TORRES faz uma didática relação das críticas ao instituto da substituição tributária "para frente", colacionando que tal figura: “a) constituiria uma obrigação tributária sem fato gerador, o que contraria a própria fenomenologia do nascimento da relação jurídica tributária no ICMS; b) importaria em desrespeito ao art. 128 do CTN, pois inexiste vínculo econômico entre o industrial e o varejista; c) haveria ofensa ao princípio da não-cumulatividade, pois não se sabe o valor real da venda ao consumidor final no momento prévio da saída da mercadoria do estabelecimento industrial $^{16,}$.

Neste sentido, é sonora a lição de Luís QUEIROZ, quando afirma que

(...) a 'Emenda no 3/93', ao 'possibilitar' que uma lei exija de alguém chamado de 'responsável' (rectius: substituto) o pagamento de um imposto ou contribuição antes de ocorrer o 'fato gerador' (rectius: fato jurídico tributário), afronta o Princípio Constitucional da Capacidade Contributiva. Pois, somente com a efetiva, real, concreta, ocorrência do fato jurídico tributário no mundo fenomênico é que se configura a capacidade contributiva por parte de alguém. O fato jurídico tributário é que revela o sinal de riqueza. Antes da sua real ocorrência (a do fato) a riqueza não existe. Logo, 'presumir' (em rigor, tornar ficção) a ocorrência do fato jurídico tributário, como estabelece a citada emenda ("fato gerador presumido' - rectius: fato jurídico tributário fictício) é fazer tabula rasa do Princípio da Capacidade Contributiva. ${ }^{21}$

Com efeito, a sujeição passiva tributária antecipada, ao fundamentar-se em fato jurídico tributário fictício, é diametralmente distinta daquela outra hipótese de substituição tributária decorrente da conjugação dos arts. 121, parágrafo único, inciso II, e 128 do CTN - de que já se tratou supra. Exatamente por não coincidir ou convergir com a figura desta substituição, e, com isso, compartilhar das duas premissas teóricas que a afinam com o princípio da capacidade contributiva (quais sejam a de o contribuinte repassar o valor a ser recolhido a título de tributo ao

\footnotetext{
${ }^{16}$ Idem. 21 Op. cit., p. 244.
} 
substituto ou a de o substituto, de posse de riqueza do substituído, reter o valor devido ao fisco), é que a substituição tributária "para frente", entre outras razões, se afigura em descompasso com a ordem constitucional. De se ressaltar, neste particular, a posição de RICARDO LOBO TORRES em sentido contrário, que para a surpresa da doutrina afirma que a “(...) EC 3/93, afinal, encerrou a controvérsia, ao acrescentar o $§ 7$ ao art. 150 (...) ${ }^{17 \%, ~ s e m ~ s e ~ a l o n g a r ~ m a i s ~ d e t i d a m e n t e ~ n a s ~ q u e s t o ̃ e s ~}$ constitucionais afeitas aos direitos fundamentais que são a pedra de toque de toda a sua obra, e, nesse sentido, classificando a substituição tributária "para frente" como uma modalidade constitucional de substituição tributária. O "passo em falso" deve-se, sobretudo, ao autor assumir, como tantos outros o fazem nas hipóteses genéricas de substituição tributária ${ }^{18}$, que haverá a pronta restituição dos valores antecipados que eventualmente se demonstrem pagos indevidamente. Porém, não foi isso que entendeu o Supremo Tribunal Federal ao julgar a ADIN n. ${ }^{\circ}$ 1.851-4/AL, tratada mais pormenorizadamente no item 4 do presente trabalho.

Assim, resta ainda a candente questão da possibilidade de restituição dos tributos pagos a maior pelo substituto, em razão do "arbitramento" dos valores devidos pelo contribuinte, decorrentes da utilização de um fato jurídico tributário fictício (que implica, por sua vez, na utilização de uma base de cálculo igualmente fictícia).

Entretanto, fosse admitida a restituição dos valores pagos a maior, o problema estaria certamente minimizado, mas não completamente resolvido, tendo em vista que, no particular que tange à sujeição passiva tributária antecipada, ainda restaria o gosto amargo de dissonar da harmonia constitucional. Por fim, sustenta ainda, com propriedade, Luís QUEIROZ que

(...) a Emenda $n^{\circ} 3 / 93$ ao autorizar que a lei estabeleça a obrigação ('O') de alguém (substituto) 'adiantar' ('p' - entregar para depois tentar receber do contribuinte) dinheiro ao Estado, permite que se institua uma restrição inconstitucional ao direito de propriedade, ou melhor, aos direitos subjetivos patrimoniais em geral (já que estas hipóteses são limitadas: tributo, desapropriação, requisição, limitações e servidões administrativas, pena e expropriação), caracterizando confisco, o que é inadmissível juridicamente - art. 150, IV, da Constituição da República (...). ${ }^{19}$

\section{A Substituição Tributária "Para Frente" nos Tribunais Superiores}

\subsection{No Superior Tribunal de Justiça (STJ):}

\footnotetext{
${ }^{17}$ Op. cit., p. 264.

${ }^{18}$ Poder-se-ia trazer à colação nomes como o de Paulo de Barros Carvalho, Marçal Justen Filho, Luís Queiroz, entre outros.

${ }^{19}$ Op. cit., p. 246. 25 Neste sentido, cf. REsp n. ${ }^{\circ} 38.529-6 / S P$, REsp n. ${ }^{\circ}$ 67.744-0/SP, EREsp n. ${ }^{\circ}$

50.884-1/SP, entre outros.
}

Revista Quaestio luris, vol.04, no01. ISSN 1516-0351 p.678-693 686 
São particularmente claras três tendências jurisprudenciais do Superior Tribunal de Justiça, igualmente bem definidas cronologicamente:

A primeira e a segunda tendências compõem, conjuntamente, uma fase inicial da Corte em que os ministros - da Primeira e Segunda Turmas da 1. a Seção -, não obstante mencionarem os Princípios constitucionais da Capacidade Contributiva e da Igualdade, divergiam entre si acerca da admissibilidade jurídica da substituição tributária "para frente", sendo que os membros da Primeira Turma rejeitavam o mecanismo ${ }^{25}$ - para tanto sustentando que o Convênio n. ${ }^{\circ}$ 66/88 foi além dos limites regulamentares (de preencher as lacunas existentes na legislação à época recepcionada e suprir aquelas do que foi não-recepcionado de Lei Complementar) que lhe permitia o art. $34, \S 8 .^{\circ}$ do ADCT, tendo sido com isso não recepcionado pela nova ordem constitucional -, e os da Segunda admitiam-no ${ }^{20}$ - sob o argumento, equivocado, de que eram distintos os momentos de ocorrência do fato gerador e o de cobrança do tributo, e que por isso a antecipação de um não conflitava com a ulterior concretização do fato gerador, sendo ambos válidos e não-contraditórios.

A terceira tendência, iniciada em meados de 1995 e, com isso, cronologicamente posterior às duas anteriores - estas relativamente concomitantes -, marca uma nova fase do Superior Tribunal de Justiça em que se estabeleceu o consenso entre os Ministros, no sentido da admissibilidade jurídica da substituição tributária para frente ${ }^{21} 22$. O ponto de convergência assentou-se basicamente na introdução do $\S 7 .^{\circ}$ ao art. 150 da CF/88 pela EC n. ${ }^{\circ} 3 / 93$, que, ao prever a substituição passiva tributária antecipada, teria "endossado" a tese de que o mecanismo estava vigente e conforme a nova sistemática constitucional. Igualmente, os ministros não fazem qualquer análise mais pontual acerca da possível inconstitucionalidade frente aos princípios informadores da ordem tributária já mencionados ao correr do presente trabalho. Atualmente, e em especial após o julgamento da ADI

1.851-4/AL pelo Supremo Tribunal Federal, esta é a posição que restou pacificada.

\subsection{No Supremo Tribunal Federal (STF):}

\footnotetext{
${ }^{20}$ Cf. a este respeito, entre outros, o REsp n. ${ }^{\circ}$ 35.570-2/SP, REsp n. ${ }^{\circ}$ 50.884-3/SP, REsp n. ${ }^{\circ}$ 53.093$8 / \mathrm{SP}$.

${ }^{21}$ Cf. as decisões, a título de exemplificação, nos EREsp n. ${ }^{\circ}$ 45.923-9/RS, EREsp n. ${ }^{\text {o } 39.413-7 / S P, ~ E R E s p ~ n . ~}{ }^{\circ}$

${ }^{22} .520 / \mathrm{SP}$, EREsp n. ${ }^{\circ}$ 35.958/SP, REsp 598.888/06/RJ, RMS 20.263/RJ, REsp 705.719/RS, REsp 256.875/RS.
} 
A questão da substituição tributária "para frente" foi posta à apreciação do Supremo Tribunal Federal de forma contundente especialmente na ADIn n. ${ }^{\circ}$ 1.851-4, do Estado de Alagoas, que foi ajuizada em 01.07.1998 pela Confederação Nacional do Comércio (CNC), questionando a constitucionalidade da cláusula segunda do Convênio ICMS n. $.^{\circ} 13 / 97$ e os $\S \S 6 .^{\circ}$ e $7 .^{\circ}$ do art. 498 do Dec. n. ${ }^{\circ} 35.245 / 91$, redação dada pelo art. 1. ${ }^{\circ}$ do Dec. n. ${ }^{\circ} 37.406$, do Estado de Alagoas.

Tal convênio pretendeu expressamente vedar a possibilidade de restituição de indébito ou cobrança complementar no caso de valores recolhidos a maior ou a menor no regime da substituição tributária antecipada - que têm como base de cálculo fato gerador presumido (ou, como já se aludiu, "fictício") -, com o intuito de prevenir uma "guerra fiscal” entre os Estados conveniados. A maioria dos ministros do STF que apreciaram a matéria na ocasião - a bem da verdade um julgamento bem mais político que propriamente jurídico - entendeu que tal restrição seria compatível com a mecânica constitucional, tendo em vista que, ipsis litteris, "A EC n. o 03/93, ao introduzir no art. 150 da $\mathrm{CF} / 88$ o $§ 7 .^{\circ}$, aperfeiçoou o instituto, já previsto em nosso sistema jurídico-tributário, ao delinear a figura do fato gerador presumido e ao estabelecer a garantia de reembolso preferencial e imediato do tributo pago quando não verificado o mesmo fato a final".

Em relação ao fato gerador presumido ou fictício já não há mais o que se falar além daquilo que se aduziu anteriormente: a própria abstração do fato gerador implica na impossibilidade fática de que este venha a produzir efeitos jurídicos, uma vez que a Constituição exige, por força do Princípio da Capacidade Contributiva, da Igualdade e da individualização do sujeito passivo, que ocorra concretamente um fato jurídico tributário, suficientemente capaz de se subsumir no antecedente de uma norma jurídica impositiva de imposto e, destarte, gerar os efeitos previstos no conseqüente da norma, concretizando-se a relação jurídica tributária. Porém, se isso por si só já vai de encontro às premissas basilares de aplicação da norma tributária e às garantias fundamentais conferidas ao sujeito passivo tributário - seja o direto, seja o seu substituto -, o que se dirá quando nem mesmo o instrumento que procurou institucionalizar a substituição tributária "para frente" coaduna-se com os referidos princípios constitucionais - inexistindo, portanto, norma jurídica impositiva de imposto, visto que a mesma sequer incorporou-se ao ordenamento constitucional, haja vista sua flagrante inconstitucionalidade.

Quanto à "garantia de reembolso preferencial e imediato do tributo pago quando não verificado o mesmo fato a final", só se pode crer que isto seja uma pilhéria jurídica. Considerar que a mera verificação objetiva e rasa do fato - qual seja o fato jurídico tributário propriamente dito - é suficiente para permitir a cobrança do tributo de acordo com o fato gerador "presumido", inclusive não ensejando a restituição ou cobrança complementar do indevidamente pago, é, com a devida 
vênia, de uma estreiteza do raciocínio jurídico que põe em cheque a autoridade e a legitimidade de uma Corte Constitucional. Ora, uma garantia de reembolso preferencial só seria verdadeira se permitisse seja a restituição do indébito, seja a cobrança complementar dos valores pagos a maior ou a menor, respectivamente. Como se não bastasse, a aplicação do regime de substituição antecipada, nos moldes como está sendo adotada, subverte a lógica jurídico-tributária da substituição passiva, de que o regime jurídico aplicável é o do substituído, e não do substituto. Uma vez que não se possibilita a devida adequação do valor antecipado ao fato jurídico tributário stricto sensu, o regime adotado não é nem o do substituído, nem o do substituto: é um regime arbitrário do Fisco. Dessa forma, ao obstar a restituição do indébito, verificamos a construção de uma verdadeira doutrina a justificar o enriquecimento ilícito por parte do Estado. Com efeito, lamentavelmente não foi em termos juridicamente escorreitos a decisão dos ministros do Supremo Tribunal Federal, que preferiram considerar que

O fato gerador presumido, por isso mesmo, não é provisório, mas definitivo, não dando ensejo à restituição ou complementação do imposto pago, senão, no primeiro caso, na hipótese de sua não realização final.

Admitir o contrário valeria por despojar-se o instituto das vantagens que determinaram a sua concepção e adoção, como a redução, a um só tempo, da máquina-fiscal e da evasão fiscal a dimensões mínimas, propiciando, portanto, maior comodidade, economia, eficiência e celeridade às atividades de tributação e arrecadação.

Como se depreende da parte final do excerto acima reproduzido, percebe-se que a decisão da Corte baseou-se mais em critérios meta-jurídicos - qual seja de política de arrecadação tributária dos Estados - do que propriamente por um raciocínio jurídico razoável. O que se fez, mais uma vez, foi adequar a realidade aos princípios e pré-concepções que se tem acerca de algo, e não o contrário, de se dobrar a uma evidência desta realidade. Comodidade e celeridade só há para o Estado, que submerso em dívidas, má-gestão administrativa e larga evasão ou desperdício de recursos, vê na antecipação da arrecadação tributária um meio contingente de equilibrar seu orçamento. Contudo, a decisão passa ao largo das garantias fundamentais do direito tributário asseguradas constitucionalmente. Se o ofício da Corte é, como acertadamente prega a doutrina constitucionalista, a de resguardar a Constituição, não foi isso o que ela fez nessa decisão: preferiu curvar-se a razões de ordem pragmática e política e, convenientemente, deixar dormitar o espírito que a anima e justifica.

De se ressalvarem, contudo, os votos em contrário dos Ministros Carlos Velloso, Celso de Mello e Marco Aurélio Mello. Argumentando que o fato jurídico tributário representado no valor da operação ou da prestação do serviço constitui o aspecto material do fato gerador, o Ministro 
Carlos Velloso defende que sem esse primeiro fato não há sequer que se falar em fato imponível a ser tributado. Apesar de considerar juridicamente válido o $\S 7 .^{\circ}$ do art. 150 da $\mathrm{CF} / 88$, o referido Ministro entende que "se o fato gerador tem, na base de cálculo, a sua expressão valorativa, ou a sua dimensão material, força é convir que o fato gerador se realiza nos termos dessa sua dimensão material, nem mais, nem menos", concluindo, portanto, que uma vez que a cláusula segunda do Convênio ICMS n. ${ }^{\circ}$ 13/97 nega a restituição do excesso de ICMS recolhido, configura-se esta como inconstitucional. Percebe-se, neste caso, que o Min. Carlos Velloso atribui uma interpretação menos draconiana à letra do $\S 7 .^{\circ}$ do art. 150 da $\mathrm{CF} / 88$, entendendo que este informa e implica a possibilidade de restituição do indébito em respeito às garantias fundamentais. O Ministro Marco Aurélio, a seu turno, repisou a questão do enriquecimento ilícito por parte do Estado, suscitando a regra proibitiva do art. $155, \S 2 .^{\circ}$ da $\mathrm{CF} / 88$, e a natureza arbitrária do fato gerador "presumido. Interessante argumento trazido no voto do Ministro Marco Aurélio é a observação de que o Estado esteja se utilizando do mecanismo da sujeição passiva antecipada como forma indireta de majoração de tributo, tendo em vista que na praxe da arrecadação tributária o Estado é particularmente eficaz em não cobrar de menos, mas sim em cobrar a mais.

Felizmente, a polêmica questão da restituição dos valores pagos a maior em razão de recolhimento antecipado em matéria de substituição tributária, não obstante a já consolidada posição do Supremo manifestada no julgamento da ADI 1.851-4/AL, está sendo novamente revisitada pelo STF - e, quem sabe, inclusive revista -, em razão do ajuizamento de duas Ações Diretas de Inconstitucionalidade admitidas em virtude da mudança na composição plenária do STF: ADI n. 2.675 e ADI n. ${ }^{\circ}$ 2.777, ajuizadas respectivamente pelos governadores dos Estados de Pernambuco e de São Paulo, desafiando previsão legislativa de restituição de impostos pagos a maior na substituição tributária para frente.

As referidas Ações Diretas de Inconstitucionalidade - ADI n. ${ }^{\circ}$ 2.675/PE e ADI n. ${ }^{\circ}$ 2.777/SP, ajuizadas a primeira em 19.06.2002 e a segunda em 02.12.2002 - questionam dispositivos de leis dos referidos Estados - art. 19, II, da Lei n. ${ }^{\circ}$ 11.408/96, do Estado de Pernambuco, e art. 66-B, II, da Lei 6.374/89, do Estado de São Paulo, com a redação dada pela Lei 9.176/95 - que asseguram a restituição do ICMS pago antecipadamente no regime de substituição tributária, nas hipóteses em que a base de cálculo da operação for inferior à "presumida" ou, mais apropriadamente, à fictícia.

A matéria encontra-se até a presente data ainda pendente de julgamento, suspensa a votação em 07.02.2007 para o voto de desempate do Min. Carlos Britto, ausente da sessão em que foi proferido o voto vista do Min. Eros Grau, que acompanhou os votos dos Ministros Nelson 
Jobim, Gilmar Mendes, Ellen Gracie e Sepúlveda Pertence, no sentido da procedência das ADI's, empatando com os votos em sentido diverso, dos Ministros Cezar Peluso (relator), Ricardo Lewandowski, Joaquim Barbosa, Marco Aurélio e Celso de Mello. Malgrado o largo período em que a matéria vem sendo discutida no plenário da Corte sem resultado definitivo - em que se pese a relevância jurídico-constitucional deste julgamento -, as decisões até o momento proferidas foram

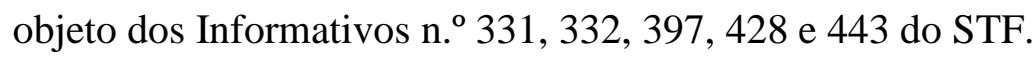

\section{Conclusão}

Considerando-se o até então exposto, e para não pecar pela redundância, cabe neste item em particular apenas sintetizar a veemente repulsa à utilização do mecanismo da substituição tributária "para frente". Malgrado ser um excelente instrumento para a administração tributária e para a sanha arrecadadora do Estado, o instituto parece chocar-se frontalmente com a sistemática constitucional.

Como precisamente conclui LUís QUEIROZ,

(...) se a Emenda Constitucional $n^{\circ}$ 3/93 veicula uma norma que autoriza a produção de outra norma, a norma impositiva de imposto ou de contribuição, tendo como antecedente a descrição de um 'fato gerador presumido' (rectius: fato jurídico tributário fictício) e como conseqüente a obrigação de um 'responsável' (rectius: substituto) pagar o imposto ou a contribuição antes da ocorrência do efetivo fato jurídico tributário, então configura-se uma total afronta aos Princípios da Capacidade Contributiva e da Igualdade, o que acarreta uma flagrante inconstitucionalidade (falta de fundamento constitucional de validade) da norma (mera mensagem prescritiva) veiculada pela referida emenda que 'autoriza' a criação da malsinada 'sujeição passiva antecipada' ou 'substituição tributária para frente'. ${ }^{23}$

Contudo, mister se faz reconhecer que, dentro do atual panorama jurídico brasileiro, dificilmente os tribunais se curvarão a tal entendimento, por melhor que seja. A deferência, ainda que inconsciente, à quase eterna raison d'Etat, a inércia que se impõe para se alterar o estado das coisas, a tensão política e institucional, tudo isso se afigura e confronta as iniciativas de se ouvir a voz da razão - e da Justiça -, razão pela qual seja razoável propor-se não a condenação do $§ 7 .^{\circ}$ do art. 150 da CF/88 ao ostracismo, mas interpretá-lo de acordo com os princípios constitucionais de forma a lapidá-lo em uma forma menos grosseira e rude.

${ }^{23}$ Op. cit., p. 247. 
Desta feita, parece que o primeiro passo está sendo realizado, a muito custo, com as duas ADIn's a que se fez referência, pendentes de julgamento. Reconhecer ao menos o direito à restituição dos valores pagos a maior pode gerar um precedente de relevo para que comece a haver um pouco de justiça fiscal no país, um pouco de contenção à fome leonina do Estado. Resta, apenas, um voto.

6. Referências Bibliográficas

BRITO, Edvaldo. ICMS - Substituição Tributária - Possibilidade ou não de Questionamento, pelo Substituído, do Valor a ser Considerado pelo Substituto. São Paulo: Revista Dialética de Direito Tributário, n. ${ }^{\circ} 97$, outubro de 2003, pp. 41-49.

CARVALHO, Paulo de Barros. Curso de Direito Tributário, 17ª ed. São Paulo: Ed. Saraiva, 2005.

COÊLHO, Sacha Calmon Navarro, DERZI, Misabel Abreu Machado. O Direito do Sujeito Passivo do ICMS de Compensar o Imposto pago a Maior, em Razão da Técnica da Substituição Tributária Progressiva. São Paulo: Revista Dialética de Direito Tributário, n. ${ }^{\circ}$ 101, fevereiro de 2004, pp. 115-135.

DE MELO, Ângelo Braga Netto Rodrigues. ICMS: Substituição Tributária Progressiva após a ADIn 1.851-4/AL - a Questão da Legitimidade dos Subsídios para Questionar a Base de Cálculo Presumida. São Paulo: Revista Dialética de Direito Tributário, n. ${ }^{\circ} 102$, março de 2004, pp. 7-21. ICMS: da Impossibilidade de Restituição/Complementação Originada de Diferença entre o Preço Presumido e o Preço Real na Substituição Tributária "para Frente". São Paulo: Revista Dialética de Direito Tributário, n. ${ }^{\circ} 71$, agosto de 2001, pp. 24-40.

MACHADO, Hugo de Brito, MACHADO SEGUNDO, Hugo de Brito. ICMS. Substituição Tributária "para frente". Critérios de Determinação do Preço Final. São Paulo: Revista Dialética de Direito Tributário, n. ${ }^{\circ} 102$, março de 2004, pp. 7-21.

MANEIRA, Eduardo. Da Substituição Tributária "para a frente" no ICMS. São Paulo: Revista Dialética de Direito Tributário, n. ${ }^{\circ}$ 92, maio de 2003, pp. 90-100.

MARTINS, Ives Gandra da Silva. As Técnicas de Arrecadação Admitidas no ICMS. São Paulo: Revista Dialética de Direito Tributário, n. ${ }^{\circ}$ 95, agosto de 2003, pp. 96-99.

. Substituição Tributária Antecipada - Inteligência Atual do $\S 7^{\circ}$ do artigo 150 da Constituição Federal - Parecer. Parecer apresentado à Advocacia Geral da União. Retirado do sítio 
www.agu.gov.br/Publicações/artigos/05042002IvesGandraSubstituiçãoTributariaAntecipada_02.pd f. Acessado em 19/01/2007.

QUEIROZ, Luís Cesar Souza de. Sujeição Passiva Tributária. Rio de Janeiro: Ed. Forense, 2002.

RIBEIRO, Antônio de Pádua. Substituição Tributária para Frente. Brasília: Revista CEJ, vol. 1, n. ${ }^{\circ}$ 3, set./dez. de 1997, p. 105-110.

SARMENTO, Daniel. Ubiquiidade Constitucional: os dois lados da moeda. Rio de Janeiro: Revista de Direito do Estado, n. 2, abril/junho de 2006, pp. 83-118.

TORRES, Ricardo Lobo. Curso de Direito Financeiro e Tributário, 12. ${ }^{\text {a }}$ ed. Rio de Janeiro: Ed. Renovar, 2005. 